\title{
EMPREGO DE ANTICONCEPCIONAIS POR UMA POPULAÇÃO BRASILEIRA
}

Célia Leitão RAMOS *

Keiko OGURA *

Daisy A. C. SOUZA *

Catherine Laura BENICZKY **

Eliana BEDINI **

Elizabeth Guedes de MEDEIROS **
Maria do Carmo Dias dos SANTOS ** Maria Eliza Fernandes CUNHA **

Marilena CASTALDELLI **

Miriam Gomes TORNANTE **

Regina Helena Corazza PELOSINI **

Rosalina NAPOLITANO **

Sonia Maria Freitas FERREIRA **

RSPU-B/199

Ramos, C. L. et al. - Emprego de anticoncepcionais por uma população brasileira. Rev. Saúde públ., S. Paulo, 8: 15-20, 1974.

RESUMO: Um grupo de 245 mulheres moradoras em Mogi das Cruzes (Estado de S. Paulo, Brasil) foi questionado com relação ao uso de anticoncepcionais, história obstétrica, mortalidade infantil $e$ atitudes correlacionadas com a limitação da natalidade. As respostas foram classificadas segundo idade e nível de renda da informante. Apenas $49 \%$ das mulheres empregavam medidas anticoncepcionais, das quais $42 \%$ recorriam aos anovulatórios. Esta prática era mais freqüente entre as mulheres jovens, e aquelas pertencentes às familias melhores situadas economicamente. Não só era mais baixa a natalidade nas mulheres que se valiam de anticoncepcionais, mas esta prática acompanhava-se de sensivel redução no número de abortos e da mortalidade infantil. $O$ efeito foi mais pronunciado entre aquelas que empregavam os anovulatorios.

Unitermos: Anticoncepcionais *; Planejamento familiar *.

Embora a questão do "planejamento familiar" tenha-se constituido, no decorrer das últimas décadas, num dos problemas mais controvertidos da atualidade, não somente na esfera da biologia mas da ética, geo-política, sociologia e economia, são escassas as informações concretas sobre a sua prática, em nosso meio.

Ao tentar contribuir, mesmo que em escala modesta, para o preenchimento des- te vazio, a equipe manteve-se rigorosamente apartidária, evitou qualquer tomada de posição durante as entrevistas, e se limitou a uma desapaixonada coleta de dados referentes ao uso de anticoncepcionais, e atitudes correlatas.

Tratando-se de mera estatística suciológica, não será tentado neste trabalho uma discussão mais pormenorizada dos resultados obtidos.

* Do Departamento de Medicina Social da Faculdade de Medicina da Universidade de Mogi das Cruzes - Rua Senador Dantas, 326 - Mogl das Cruzes, SP, Brasil.

* Acadêmicas da Faculdade de Medicina da Universidade de Mogi das Cruzes. 
RAMOS, C. L. et al. - Emprego de anticoncepcionais por uma população brasileira. Rev. Saúde públ., S. Paulo, 8: 15-20, 1974.

\section{MATERIAL E METODOS}

O presente estudo foi levado à efeito na área urbana de Mogi das Cruzes (Estado de S. Paulo), onde foram entrevistadas, a domicílio, um total de 245 donas de casa, selecionadas através de uma amostragem casual em dois estágios, repetida para cada um dos 42 quadrados em que foi subdividida a planta da cidade.

Em se tratando de um questionário constituído, principalmente, de "perguntas abertas" (ver Anexo), não só o questionário mas a própria atitude dos entrevistadores foram previamente testados em 20 famílias (aqui não incluídas). Esta rigorosa padronização da conduta de inquérito assegura, a nosso ver, a exatidão das conclusôes apresentadas.

Lim segundo grupo de mulheres, em número de 100 (e que não foi incluído nas tabelas), foi entrevistado na sala de espera de um dos ambulatórios do INPS. sem qualquer critério de seleção. Quanto à idade e demais variáveis (exceto nível de renda) este segundo grupo aproximava-se surpreendentemente da amostra de 245 mulheres, já discutida. O total de 50 pacientes referia uso de medidas anticoncepcionais.

Esta população de 100 mulheres foi utilizada para investigar a receptividade à um hipotético ambulatório, especializado em "planejamento familiar", e cujos serviços seriam inteiramente gratuitos.

\section{R ESULTA D O S}

Setenta e oito por cento das mulheres eram casadas no civil e religioso. $14 \%$ apenas no civíl, e a quase totalidade das restantes eram viuvas ou desquitadas (apenas 3 confessaram ser amasiadas). Vinte e cinco por cento eram analfabetas, $31 \%$ tinham curso primário incompleto, $30 \%$ o haviam completado, tendo as demais nível de instrução mais avançado. Com respeito à religião, $62 \%$ eram católicas, $24 \%$ não sabiam informar a crença(!), as restantes distribuindo-se por 10 diferentes religiōes ou seitas.

A distribuição etária está reproduzida na Tabela 1 .

TABELA 1

Distribuição etária das 245 mulheres entrevistadas

\begin{tabular}{|c|c|c|}
\hline $\begin{array}{l}\text { Idade } \\
\text { (anos) }\end{array}$ & Número & $\tau_{0}$ \\
\hline $10-19$ & 6 & 25 \\
\hline $20-29$ & 66 & 27,0 \\
\hline $30-39$ & 95 & 38,5 \\
\hline $40-49$ & 55 & 22,5 \\
\hline Mais de 50 & 23 & 9,5 \\
\hline Total & 245 & 100,0 \\
\hline
\end{tabular}

TABELA 2

Distribuição quanto à idade do matrimônio no grupo em questão

\begin{tabular}{l|c|c}
$\begin{array}{c}\text { Casadas há } \\
\text { (anos) }\end{array}$ & Número & $\%$ \\
\hline $0-4$ & 31 & 12,6 \\
$5-9$ & 50 & 20,5 \\
$10-14$ & 44 & 18,0 \\
$15-19$ & 43 & 17,5 \\
$20-24$ & 40 & 16,3 \\
$25-29$ & 19 & 7,7 \\
Mais de 30 & 18 & 7,4 \\
\hline Total & 245 & 100,0 \\
\hline
\end{tabular}

T A B E L A 3

Distribuição por renda da família

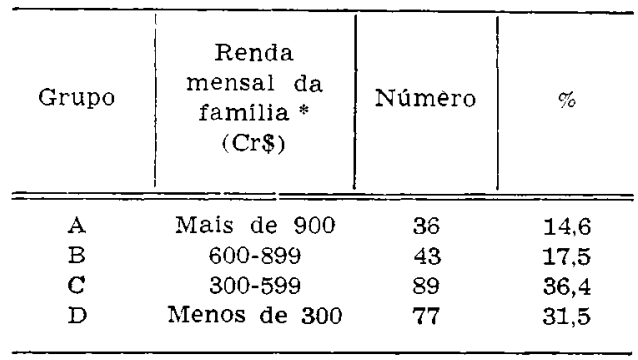

* Este trabalho foi realizado em 1969-70́. 
RAMOS, C. L. et al. - Emprego de anticoncepcionais por uma população brasileira. Rev. Saúde públ., S. Paulo, 8: 15-20, 1974.

A Tabela 2, por seu turno, fornece a distribuição segundo idade do matrimônio.

Com respeito ao nivel de renda da família, a sua distribuição consta da Tabela 3 .
A Tabela 4 reproduz a história obstétrica destas 245 mulheres, sendo classificada segundo o nível de renda.

Com respeito ao emprego de métodos anticoncepcionais, 120 mulheres $(49 \%)$ informaram utilizar-se de algum dos re-

TABELA 4

História obstétrica das 245 mulheres, com relação ao nivel de renda

\begin{tabular}{|c|c|c|c|c|c|c|c|c|c|}
\hline \multirow{2}{*}{ Grupo } & \multirow{2}{*}{$\begin{array}{l}\text { Número } \\
\text { de } \\
\text { mulheres }\end{array}$} & \multicolumn{2}{|c|}{ Fílhos vivos } & \multicolumn{2}{|c|}{ Filhos mortos } & \multicolumn{2}{|c|}{ Abortos } & \multicolumn{2}{|c|}{ Gestações } \\
\hline & & Total & $\begin{array}{c}\text { Por } \\
\text { familia }\end{array}$ & Total & $\begin{array}{c}\text { Por } \\
\text { família }\end{array}$ & Total & $\begin{array}{c}\text { Por } \\
\text { família }\end{array}$ & Total & $\begin{array}{c}\text { Por } \\
\text { familia }\end{array}$ \\
\hline$A$ & 36 & 104 & 2,88 & 6 & 0,17 & 14 & 0,39 & 124 & 3,44 \\
\hline B & 43 & 133 & 3,10 & 21 & 0,49 & 13 & 0,30 & 167 & 3,88 \\
\hline C & 89 & 338 & 3,80 & 57 & 0,62 & 45 & 0,50 & 440 & 4,94 \\
\hline D & 77 & 285 & 3,70 & 73 & 0,95 & 57 & 0,74 & 415 & 5,39 \\
\hline
\end{tabular}

T A B E I A 5

Uso de medidas anticoncepcionais

\begin{tabular}{l|rr}
\hline \multicolumn{1}{c}{ Método } & \multicolumn{2}{|c}{ Usam } \\
\cline { 2 - 3 } & Numero & $\%$ \\
\hline Anovulatórios & 54 & 20,9 \\
Coitus interruptus & 21 & 8,6 \\
Preservativos de borracha & 13 & 5,3 \\
Ritmo & 16 & 6,5 \\
Lavagens & 5 & 2,0 \\
Supositórios vaginais & 3 & 1,2 \\
Ligadura das trompas & 7 & 2,9 \\
Outros * & 4 & $\mathbf{1 3} 6$ \\
Nảo usam & $\mathbf{1 2 5}$ & $\mathbf{5 1 , 0}$ \\
\end{tabular}

* Duas mulheres referiam empregar um DIU. cursos disponiveis, conforme discriminado na Tabela 5 .

Uma atitude favorável ou contrária à limitação da natalidade não é uniformemente distribuída através da população; sua relação com as duas variáveis idade e nível de renda está exposta nas Tabelas 6 e 7 .

\section{DISCUSAO}

Grande parte destas questóes parecem tão óbvias que dispensariam maiores comentários, podendo os resultados mesmo serem antecipados. Assim, não causa es-

T A B E L A 6

Uso de medidas anticoncepcionais em funcão da idade

\begin{tabular}{|c|c|c|c|c|c|}
\hline \multirow{2}{*}{ Idade (anos) } & \multirow{2}{*}{$\begin{array}{l}\text { Número de } \\
\text { mulheres }\end{array}$} & \multicolumn{2}{|c|}{ Usam anticoncepcionais } & \multicolumn{2}{|c|}{ Usam anovulatórios } \\
\hline & & N.o & $\%$ & N.O & $\%$ \\
\hline $10-19$ & 6 & 2 & 30,3 & 0 & - \\
\hline $20-29$ & 66 & 44 & 66,7 & 35 & 50,3 \\
\hline $30-39$ & 95 & 53 & $\mathbf{5 5 , 8}$ & 15 & 15,8 \\
\hline $40-49$ & 55 & 17 & 30,9 & 3 & 5,5 \\
\hline Mais de 50 & 23 & 4 & 17,5 & 0 & - \\
\hline
\end{tabular}


RAMOS, C. L et al. - Emprego de anticoncepcionais por uma população brasileira. Rev. Saúde piibl., S. Paulo, 8: 15-20, 1974.

\section{TABEA 7}

Uso de medidas anticoncepcionals em função do nivel de renda

\begin{tabular}{|c|c|c|c|c|c|}
\hline \multirow{2}{*}{ Grupo } & \multirow{2}{*}{$\begin{array}{l}\text { Número de } \\
\text { mulheres }\end{array}$} & \multicolumn{2}{|c|}{ Usam anticoncepcionais } & \multicolumn{2}{|c|}{ Usam anovulatórios } \\
\hline & & N.o & $\%$ & N.O & $\%$ \\
\hline A & 33 & 29 & 80,6 & 13 & 36,1 \\
\hline B & 43 & 26 & 60,5 & 12 & 27,9 \\
\hline C & 89 & 45 & 50,5 & 17 & 19,1 \\
\hline D & 77 & 20 & 25,9 & 11 & 14,3 \\
\hline
\end{tabular}

TABELA 8

História obstétrica das 245 mulheres, em função do uso de medidas anticoncepcionais

\begin{tabular}{|c|c|c|c|c|c|c|c|c|c|}
\hline \multirow{2}{*}{ Aitude } & \multirow{2}{*}{$\begin{array}{l}\text { Número } \\
\text { de } \\
\text { mulheres }\end{array}$} & \multicolumn{2}{|c|}{ Filhos vivos } & \multicolumn{2}{|c|}{ Filhos mortos } & \multicolumn{2}{|c|}{ Abortos } & \multicolumn{2}{|c|}{ Gestaçōes } \\
\hline & & Total & $\begin{array}{c}\text { Por } \\
\text { familia }\end{array}$ & Total & $\begin{array}{c}\text { Por } \\
\text { familia }\end{array}$ & Total & $\begin{array}{c}\text { Por } \\
\text { familia }\end{array}$ & Total & $\begin{array}{c}\text { Por } \\
\text { família }\end{array}$ \\
\hline $\begin{array}{l}\text { Não } \\
\text { controlam }\end{array}$ & 125 & 550 & 4,40 & 122 & 0,98 & 84 & 0,67 & 756 & 6,05 \\
\hline $\begin{array}{l}\text { Usam ano- } \\
\text { vulatóríos }\end{array}$ & 53 & 129 & 2,43 & 12 & 0,23 & 13 & 0,25 & 154 & 2,90 \\
\hline $\begin{array}{l}\text { Usam outros } \\
\text { métodos }\end{array}$ & 67 & 181 & 2,70 & 23 & 0,34 & 32 & 0,48 & 236 & 3,52 \\
\hline
\end{tabular}

pécie que o uso de anticoncepcionais é mais comum entre os 20 e 40 anos, justamente quando é mais ativa a vida sexual da mulher. Pode igualmente parecer banal a constatação de que esta prática é mais difundida entre as classes mais abastadas, que não somente tem mais fácil acesso ao aconselhamento médico, mas para as quais a despesa com medicamentos ou dispositivos não representa ônus apreciável.

Mas o raciocínio apriorístico é perigoso, particularmente quando as conclusões parecem por demais óbvias. Examinemos, por exemplo, um dos postulados: serão, efetivamente, os obstáculos de ordem econômica aqueles responsáveis pelo não emprego dos anovulatórios em fração tão considerável dos grupos $C$ e $D$ ?
Perguntando-se às mulheres que não praticavam o controle de natalidade (6 das quais desconheciam inteiramente a existência de semelhantes recursos) qual o motivo de sua abstenção, verificou-se que em somente $6 \%$ esta atitude deviase a motivos económicos. Por outro lado, $38 \%$ acreditavam que a prática anticoncepcional prejudicava a saúde, $24 \%$ queriam ter mais filhos, $4 \%$ apelavam à considerações religiosas, enquanto que nas restantes $16 \%$ existiam motivos de ordem psicológica, um mal definido "medo", não especificamente ligado à saúde.

Mas as variáveis econômicas constituiam o argumento mais frequentemente lembrado pelas mulheres que desejavam evitar gestaçōes futuras, constituindo $60 \%$ do total de respostas. $O$ bem-estar eco- 
RAMOS, C. L. et al. - Emprego de anticoncepcionais por uma população brasileira. Rev. Saúde públ., S. Paulo, 8: 15-20, 1974.

nômico é, pois, critério relativo, já que a limitação da natalidade é mais comum entre as classes em melhor situação financeira.

Verificou-se, no segundo grupo de mulheres, que $35 \%$ se desinteressavam totalmente por um serviço gratuito de "planejamento familiar", cifra evidentemente maior $(70 \%)$ entre aquelas que não empregavam medidas anticoncepcionais.

0 emprego de medidas anticoncepcionais não é uma prática empreendida aleatoriamente - novamente uma afirmação que se poderia fazer a priori. Enquanto que $36 \%$ das mulheres que não usam anticoncepcionais desejam ter mais filhos, apenas $22 \%$ daquelas que usam estes métodos expressaram semelhante vontade.

É mais do que natural, também, que a prática da limitação dà natalidade venha a traduzir-se em prole menos numerosa, como é ilustrado através da Tabela 8.

Surgirá, evidentemente, a suspeita de que também estes dados são absolutamente previsíveis, não constituindo qualquer surpresa. Com efeito, se o emprego de medidas anti-concepcionais $\dot{e}$ menos freqüente nas mulheres com mais de 40 anos (Tabela 6), uma prole mais numerosa neste grupo de mulheres que não procura limitar a natalidade não falaria a favor da eficiência dos métodos usados, mas traduziria, muito simplesmente, uma história obstétrica mais prolongada.

Mas esta relação de causa efeito é apenas aparente. Em primeiro lugar, apenas $32 \%$ das 245 mulheres contava com mais de 40 anos, e não é total neste grupo a abstenção de anticoncepcionais. Em segundo lugar, é mais ou menos idêntica a distribuição etária nos quatro grupos de nivel de renda (dados aqui não reproduzidos), embora tenha sido constatada acentuada disparidade em sua história obstétrica (Tabela 4). E nota-se outra diferença: enquanto que o número de filhos vivos para as mulheres que empregam anovulatórios é $55 \%$ daquele das mulheres que não empregam nenhum dos métodos, o número de filhos morto é de $24 \%$ e o número de abortos $37 \%$ do grupo tomado como base (Tabela 8).

Os dados da Tabela 8 permitem, efetivamente, diferentes intespretações, a mais óbvia das quais lembra que o uso de medidas anticoncepcionais é fator determinado pela cultura, e que esta mesma cultura também é propícia à utilização de serviços médicos (pré-natal, puericultura). A mulher suficientemente motivada para empreender a limitação da natalidade também teria propensão para valorizar mais intensamente a saúde dos filhos, cuja existência é devida a um ato de conciente escolha. Aceitar semelhante tese refutaria o postulado, a nosso ver bastante ingênuo, de que bastaria fornecer anticoncepcionais a uma população para resolver, como por encanto, todos os problemas ligados à saúde materno-infantil.

No presente trabalho, os autores deliberadamente se omitiram a uma discussão mais pormenorizada de seus achados, bem como evitaram traçar um paralelo entre os mesmos e a literatura mundial, primeiro por acreditarem pisar em terreno ainda inseguro, segundo por estarem conscientes de que uma comparação seria infrutífera enquanto estudos de cunho mais amplo não puderem ser levados a efeito.

\section{CONCLUSOES}

1. Das 245 mulheres questionadas, apenas $49 \%$ empregavam medidas anticoncepcionais, cuja prática era mais freqüente entre as mulheres jovens, e aquelas pertencentes às famílias melhores situadas economicamente.

2. A baixa natalidade nas mulheres que usavam anticoncepcionais era acompanhada de sensível redução do número de abortos e de mortalidade infantil. 
RAMOS, C. L. et al. - Emprego de anticoncepcionais por uma populaçăo brasilelra. Rev. Saúde pübl., S. Paulo, 8: 15-20, 1974.

RSPU-B/199

RAMos, C. L. et al. - [Use of contraceptive practices by a Brazilian population]. Rev. Saúde públ., S. Paulo, 8: 15-20, 1974 .

SummaRx: A group of 245 married women from Mogi das Cruzes (State of S. Paulo, Brazil were questioned about the use of contraceptive practices, past obstetric history, child mortality, and attitude toward birth control. Answers were classified according to age and family earnings. Only $49 \%$ of these women practiced contraception, $42 \%$ of which used the "pill". There was a positive correlation between the practice of birth control and wage levels, and contraception was like-wise more common in the younger age groups. The natality was reduced considerably in those women who availed themselves of contraception and also it was observed a drastic decrease in the number of abortions and in child mortality. This effect was more pronounced in those who used the anovulatory drugs.

UNITERMS: Contraception*; Family planning*.

Recebido para publicação em 4-9-1979

Aprovado para publicaç̃o em 21-1-1974

\section{A N EXO}

Departamento de Medicina Social

Dr. Kurt Kloetzel

Nome da dona de casa:

Endereço

Nome do aluno:

1. Idade da entrevistada:....... anos

2. Tempo de casamento:....... anos

3. Sabe ler? ( ) sim ( ) não

4. Renda familiar mensal: Cr\$..............

5. História das gestações anteriores:

n." de filhos vivos: .......

n. ${ }^{\circ}$ de filhos mortos: ........

n..$^{\circ}$ de abortos espontâneos: ........

$n .^{\circ}$ de abortos provocados: ........

6. Quer ter mais filhos? ( ) sim ( ) não

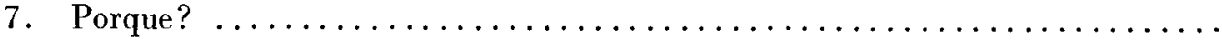

8. Usa algum método para evitar filhos? ( ) sim ( ) não .......

(OBs.: Se a entrevistada não usa nenhum método, passe para a pergunta $n .^{\circ} 12$ )

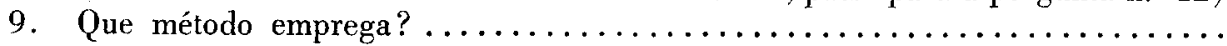

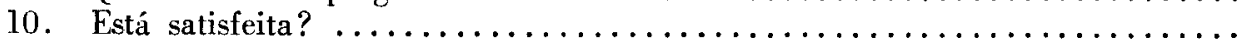

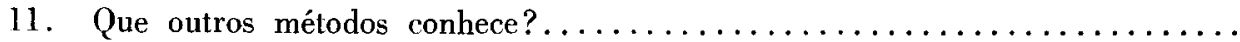

12. Porque não usa? 